\title{
ASSOCIATION OF BLOOD PRESSURE WITH BODY MASS INDEX AND FAMILY HISTORY OF HYPERTENSION AMONG MEDICAL STUDENTS OF TERTIARY CARE TEACHING HOSPITAL IN BIRGUNJ.
}

\author{
Esha Shrestha $^{1^{*}}$, Shreesh Shrestha ${ }^{2}$, Prashanna Shrestha ${ }^{3}$, Nirjala Laxmi Madhikarmi ${ }^{4}$
}

\section{Affiliation}

1. Lecturer, Department of Clinical Physiology, Kantipur Dental College and Teaching Hospital, Nepal

2. Resident, Department of Gastroenterology, Virginia Commonwealth University, USA

3. Lecturer, Department of Clinical Physiology, Kantipur Denta College and Teaching Hospital, Nepal

4. Associate Professor, Department of Biochemistry, Kantipur Dental College and Teaching Hospital, Nepal

\section{ARTICLE INFO}

Received : 23 June, 2021

Accepted : 22 July, 2021

Published : 04 November, 2021

(C) Authors retain copyright and grant the journal right of first publication with the work simultaneously licensed under Creative Commons Attribution License CC - BY 4.0 that allows others to share the work with an acknowledgment of the work's authorship and initial publication in this journal.

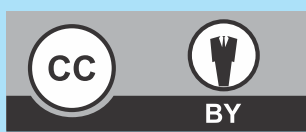

ORA 265

DOI: https://doi.org/10.3126/bjhs.v6i2.40354

* Corresponding Author

Dr. Esha Shrestha

Lecturer

Department of Clinical Physiology

Kantipur Dental College and Teaching Hospital, Nepal

Email: dr.estha@gmail.com

ORCID: https://orcid.org/0000-0002-4503-9975

\section{Citation}

Esha Shrestha, Shreesh Shrestha, Prashanna Shrestha, Nirjala Laxmi Madhikarmi. Association of Blood Pressure with Body Mass Index and Family History of Hypertension Among Medical Students of Tertiary Care Teaching Hospital in Birgunj. BJHS 2021;6(2)15. 1535-1539.

\section{ABSTRACT}

\section{Introduction}

Body mass index is an important parameter associated with a variety of disease processes. Hypertension is one of the major risk factor associated with cardiovascular disease. The risk of hypertension and cardiovascular diseases increases with an increase in body mass index.

\section{Objective}

To evaluate the prevalence of obesity and hypertension in medical students and correlate blood pressure with body mass index and family history of hypertension.

\section{Methodology}

The study was conducted in 200 students (113 males and 87 females). Height, weight and blood pressure were recorded from all participants and body mass index was calculated. The recorded body mass index was utilized to divide the student into underweight, normal, over weight and obese category according to the World Health organization body mass index classification. Hypertension was determined from the measure of blood pressure. Then comparison of blood pressure with body mass index and family history of hypertension was made.

\section{Result}

Among 200 students $6 \%$ were obese, $22 \%$ were overweight, $65 \%$ were normal and $7 \%$ underweight. The mean height was $163 \mathrm{~cm}$ and mean weight $60.48 \mathrm{~kg}$. The mean value of systolic blood pressure $(105.85,115.45,134.95,137.16$ $\mathrm{mmHg}$ ) and diastolic blood pressure $(70.14,76.15,90.72$, $93.33 \mathrm{mmHg}$ ) increased with increasing body mass index. Prevalence of obesity and hypertension both are more in male students than that of female students. Family history of hypertension is significantly associated with hypertension in male students than female students.

\section{Conclusion}

Overweight, obesity and family history of HTN increases the risk of hypertension among students.

\section{KEYWORDS}

Body mass index; Blood pressure; Hypertension; Obesity; Overweight 


\section{INTRODUCTION}

Obesity is one of the of increasing problem of developing nations. ${ }^{1}$ Differences in the lifestyle, dietary pattern, and physical activities are the main contributors of overweight and obesity within the country. ${ }^{2}$ Overweight and obesity increase the risks of high BP (Blood Pressure), coronary heart disease, diabetes mellitus, and certain cancers. ${ }^{3}$ Hypertension $\{\mathrm{HTN}\}$ is one of the major risk factors associated with cardiovascular diseases, which is also a component of the metabolic syndrome. ${ }^{4,5}$

According to the global World Health Organization (WHO), the worldwide prevalence of overweight and obesity in 2008 among adults was more than 1.4 billion. The prevalence of hypertension (HTN) varies from $3.8 \%$ to $24.8 \%$ in youth with overweight and obesity.About $62 \%$ of cerebrovascular disease and $49 \%$ of ischemic heart disease are attributable to suboptimal BP ie, systolic 115 $\mathrm{mm} \mathrm{Hg}$. About $58 \%$ of the global cases of diabetes mellitus and $21 \%$ of ischemic heart diseases were caused by BMI above $21 \mathrm{~kg} / \mathrm{m} 2{ }^{6}$

Increased cases of obesity, hypertension and cardiovascular diseases in young generation in developing countries are quite alarming. Despite a growing burden of obesity and hypertension, there is limited information on the contribution of BMI (Body Mass Index) to BP in these populations. This study was conducted to look at the association with BP with BMI and family history of HTN in young medical students. This study intends to generate relevant information that helps to understand the patterns of high BP in lean and obese populations.

\section{METHODOLOGY}

A descriptive cross-sectional study was conducted on $1^{\text {st }}$ and $2^{\text {nd }}$ year medical students from March 2020 to March 2021. Ethical approval was obtained from the institutional review committee (ref no:418/077/076.) in February 2020. The study comprises of 113 males and 87 females, age ranging from 17 to 25yrs.The students who were willing to participate were considered and students who were taking any medication for hypertension or obesity or who were suffering from any systemic disease were excluded from study. Sample size was calculated using the formula as given below:

$$
\begin{aligned}
\mathrm{C} & =0.5^{*} \ln [(1+r) /(1-r)]=0.2027 \\
\mathrm{~N} & =[(\mathrm{Z} \alpha+Z \beta) / C]^{2}+3 \\
& =\left[(1.9600+0.8416 / 0.2027]^{2}+3\right. \\
& =194 \\
& \approx 200
\end{aligned}
$$

Where $\alpha=$ Type I error and standard normal deviation for

$$
\alpha=Z \alpha
$$

$\beta=$ Type II error and standard normal deviation for $\beta=Z \beta$

$\mathrm{C}=$ Correlation co-efficient

$\mathrm{N}=$ sample size

The participated students were screened through a medical history questionnaire, physical examination and blood pressure. After taking written informed consent, data were collected through structured questionnaire. The questionnaire contained information regarding gender, current year of study of MBBS, family history of HTN, food habit, exercise and drug history. The measurements of blood pressure were taken through pre-checked and reliable apparatus i.e., mercury sphygmomanometer. The students were seated calm and quiet for at least 5 minutes prior to measurement on comfortable chairs. For categorization of blood pressure World Health Organization(WHO) classification was used according to which students having blood pressure of systolic $120-129$ and diastolic less than 80 is considered as pre hypertensive, systolic 130-139 and diastolic between 80 89 is consider as stage 1 and systolic more than 140 and diastolic more than 90 was consider as stage 2 hypertension. ${ }^{7}$

Three consecutive readings of BP were recorded in morning at the interval of 3 minutes between consecutive measurements in sitting position and mean were calculated. Weight and height were measured with subjects standing without shoes and wearing light clothes. Students stood upright with the head in Frankfort plane for height measurement which was done by stadiometer. Weight was measured by asking student to stand straight in digital weighing machine. Height was recorded to the nearest $0.5 \mathrm{~cm}$ and weight was recorded nearest $100 \mathrm{~g}$. BMI was then calculated through standard formula i.e., weight $(\mathrm{kg}) /$ height $\left(\mathrm{m}^{2}\right)$ and was categorized according to WHO classification into 4 categories i.e. underweight $<18.5$, Normal weight 18.5 -24.9 , Over weight $25-29.9$ and Obese $>30 \mathrm{~kg} / \mathrm{m}^{2}$.

Data were entered in SPSS version 16.0. Descriptive analysis of $\mathrm{BP}$, weight, height and $\mathrm{BMI}$ were calculated and comparison done on BP among BMI of the group. We used Chi-square test and Pearson correlation to analyze the correlation between HTN, BMland family history of HTN in students. $\mathrm{P}$-value of $<0.05$ was taken significant.

\section{RESULTS}

The study included 200 medical students of $1^{\text {st }}$ and $2^{\text {nd }}$ year with a mean age of 20.46 where 113 were males and 87 were females. (Fig 1) The height was measured in centimeter with mean height of $163 \pm 29.14 \mathrm{~cm}$ and the weight was measure in kilogram with mean weight of 60.48 $\pm 11.04 \mathrm{~kg}$. About $76 \%$ students are in habits of taking junk food. Nearly $62.83 \%$ males and $68.96 \%$ females fell under normal weight and about $24.77 \%$ males and $18.39 \%$ females are overweight (Table 1 ). About $14 \%$ males and $21 \%$ females have normal systolic blood pressure and $14 \%$ males and $21.5 \%$ females have normal diastolic blood pressure. While

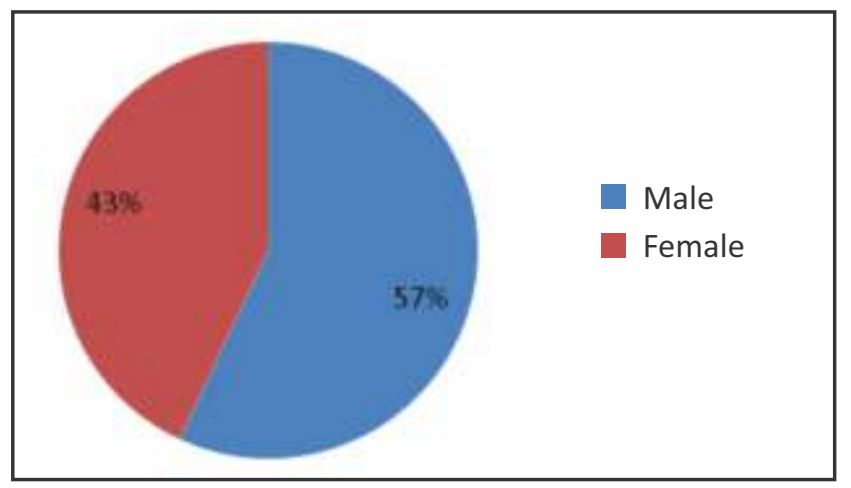

Figure 1: Distribution of male and female students 
$33.5 \%$ males and $19.5 \%$ females have high systolic blood pressure and $23 \%$ males and $17 \%$ females have high diastolic blood pressure (Table 2 ) indicating the prevalence of obesity and hypertension is more in males than females.

Mean value of systolic BP $(105.85,115.43,134.95,137.16)$ and diastolic BP $(70.14,76.15,90.72,93.33)$ were found to be higher as the BMI increased (Table 3).

The family history of HTN in underweight, normal, over weight and obese were $3.15 \%, 56.84 \%, 30.52 \%, 9.47 \%$ respectively (Table 4).The family history of HTN and HTN in male students is highly significant $(<0.05)$ but the family history of HTN in female is not significant (>0.05). (Table 5)

The association of BMI with systolic and diastolic blood pressure had significant positive correlation with $p<0.005$ and $r$ $=0.699$ (systolic) and $\mathrm{p}<0.005$ and $\mathrm{r}=0.708$ (diastolic) (Table:6).

\begin{tabular}{|c|c|c|c|c|c|}
\hline \multirow[t]{2}{*}{ Sex } & \multicolumn{4}{|c|}{ Body mass index } & \multirow[t]{2}{*}{ Total } \\
\hline & $<18.5$ & $18.5-24.9$ & $25-29.9$ & $>30$ & \\
\hline Male(n) & 7 & 71 & 28 & 7 & 113 \\
\hline Female(n) & 6 & 60 & 16 & 5 & 87 \\
\hline Total (n) & 13 & 132 & 43 & 12 & 200 \\
\hline
\end{tabular}

Table 2: Sex and blood pressure cross tabulation

\begin{tabular}{|l|c|c|c|}
\hline \multicolumn{1}{|c|}{ Systolic BP } & $\begin{array}{c}\text { Male } \\
(\mathbf{n})\end{array}$ & $\begin{array}{c}\text { Female } \\
(\mathbf{n})\end{array}$ & $\begin{array}{c}\text { Total } \\
(\mathbf{n})\end{array}$ \\
\hline$<120$ & 28 & 42 & 70 \\
\hline $120-139$ & 67 & 39 & 106 \\
\hline $140-159$ & 18 & 6 & 24 \\
\hline$>160$ & 0 & 0 & 0 \\
\hline Diastolic BP & & & \\
\hline$<80$ & 28 & 43 & 71 \\
\hline $80-89$ & 46 & 34 & 80 \\
\hline $90-99$ & 24 & 8 & 32 \\
\hline$>100$ & 15 & 2 & 17 \\
\hline
\end{tabular}

Table 3: Mean BP in each BMI category.

\begin{tabular}{|c|c|c|}
\hline $\begin{array}{c}\text { Body Mass Index } \\
<\mathbf{1 8 . 5}\end{array}$ & $\begin{array}{c}\text { Mean Systolic BP } \\
\mathbf{1 0 5 . 8 5} \pm 9.26\end{array}$ & $\begin{array}{c}\text { Mean Diastolic BP } \\
\mathbf{7 0 . 1 4 \pm 7 . 2 2}\end{array}$ \\
\hline $18.5-24.9$ & $115.43 \pm 10.54$ & $76.15 \pm 7.68$ \\
\hline $25-29.9$ & $134.95 \pm 9.72$ & $90.72 \pm 6.48$ \\
\hline$>30$ & $137.16 \pm 11.64$ & $93.33 \pm 9.16$ \\
\hline
\end{tabular}

Table 4: Family history of HTN and Body mass index cross tabulation

\begin{tabular}{|c|l|c|c|c|c|c|}
\hline \multirow{2}{*}{} & & \multicolumn{4}{|c|}{ Body mass index of students } & Total \\
\cline { 2 - 7 } & & $<\mathbf{1 8 . 5}$ & $\mathbf{1 8 . 5 - 2 4 . 9}$ & $\mathbf{2 5 - 2 9 . 9}$ & $\mathbf{> 3 0}$ & \\
\hline \multirow{2}{*}{$\begin{array}{c}\text { Family H/0 of } \\
\text { HTN }\end{array}$} & Yes (n) & 3 & 54 & 29 & 9 & 95 \\
\cline { 2 - 7 } & No (n) & 11 & 76 & 15 & 3 & 105 \\
\hline & Total (n) & 14 & 130 & 44 & 12 & 200 \\
\hline
\end{tabular}

Table 5: Family history of HTN and HTN in off spring cross tabulation

\begin{tabular}{|c|c|c|c|c|c|}
\hline \multirow[t]{2}{*}{ Sex } & \multicolumn{2}{|c|}{ Family H/O HTN } & \multicolumn{2}{|c|}{$\begin{array}{l}\text { HTN in offspring/ } \\
\text { students }\end{array}$} & \multirow[t]{2}{*}{$P$ value } \\
\hline & Yes & No & Yes & No & \\
\hline Male(n) & 44 & 69 & 44 & 69 & 0.002 \\
\hline Female(n) & 48 & $z 39$ & 16 & 71 & 0.227 \\
\hline
\end{tabular}

Table 6: Pearson Correlation of BMI and BP

\begin{tabular}{|l|l|l|l|l|}
\hline & \multicolumn{1}{|c|}{ SBP } & & \multicolumn{1}{c|}{ DBP } & \\
\hline & P valve & r value & P value & r value \\
\hline BMI & 0.000 & 0.699 & 0.000 & 0.708 \\
\hline
\end{tabular}

*Correlation is significant at 0.01 level

\section{DISCUSSION}

The present study provides an idea about the association between BMI and BP in students which has important implications for the risk of cardiovascular disorder in future. The result of present study showed that there is strong association between BMI and SBP or DBP among medical students as the $\mathrm{BMI}$ increases the $\mathrm{BP}$ also increases significantly. Our finding is similar to a study done by N. K. Mungreiphy who found BMI as a strong predictor of blood pressure.

Underweight subjects were less likely to have high blood pressure than those who were in normal BMI category. Overweight or obese subjects were more likely to have significantly higher blood pressure than those with normal BMI. Kumanyika et al. have shown body mass index to be even more strongly associate with the blood pressure than race. ${ }^{9}$ Humayun et al. indicated strong association of hypertension to $\mathrm{BMI}$ rather than age. ${ }^{10}$ But the studies done by Schall, indicate that high BP is associated with age and is because of the process of modernization. ${ }^{11} \mathrm{P}$. Bovet also reported that a significantly higher mean systolic and diastolic blood pressure among urban men than that of rural men in elderly populations of North India. ${ }^{12}$

The study performed by Robert Whitaker et al., observed that obese children under three years of age without having obese parents are at low risk for obesity in adult, but among the older children, obesity is an increasingly important predictor of adult obesity, no matter whether the parents are obese or not. ${ }^{13}$ In our study the family history of HTN is more in obese students. Generally, overweight and obese adolescents have more body fat and higher blood pressure than normal weight adolescents, and a strong relation between BMI and bloodpressure is well established for both systolic and diastolic blood pressure. ${ }^{14}$

The Framingham Study demonstrated that both men and women had an increase in blood pressure with increased overweight. ${ }^{15}$ The systolic blood pressure increased $4 \mathrm{mmHg}$ for every $4.5 \mathrm{~kg}$ of increased weight. ${ }^{15}$ In our study higher body mass index had about $14 \mathrm{mmHg}$ higher systolic blood pressure and $10 \mathrm{mmhg}$ higher diastolic blood pressure than students in lower body mass index. In the younger adults, men and women with a body mass index of more than 30 $\mathrm{kg} / \mathrm{m} 2$ had a 5 times higher prevalence of hypertension than persons with a body mass index less than $20 \mathrm{~kg} / \mathrm{m} 2 .{ }^{16}$ Compared with a weight change of $2 \mathrm{~kg}$ or less, the risk of hypertension was $15 \%$ less in women who lost 5 to $9.9 \mathrm{~kg}$, $26 \%$ less in women who lost $10 \mathrm{~kg}$ or more, increased $74 \%$ in women who gained 5 to $9.9 \mathrm{~kg}$, and increased 5.21 times in women who gained $25 \mathrm{~kg}$ or more. ${ }^{17}$ In the nationwide Community Hypertension Evaluation Clinic screening of 
more than 1 million men and women, the prevalence of hypertension in overweight persons aged 20 to 39 years was twice that of persons with a normal weight and 3 times higher than that of underweight persons. ${ }^{18}$ Changes in body fat over 8 years were associated with changes in both systolic and diastolic blood pressure. Becoming normal weight reduced the risk of developing hypertension to a level similar to persons who were never obese. ${ }^{19}$

Hypertension is directly associated to $\mathrm{BMI}$; it shows that increase in BMI leads to increase in the trend of hypertension in both male and female students. Our study revealed that obesity prevalence for males is more than that of females (males: $30.96 \%$ and females: $24.13 \%$ ). Similar results have been reported from china ${ }^{20}$ and Taiwan. ${ }^{21}$ The $\mathrm{BP}$ in our study is also higher in male than female. The study done by Krzyzaniak, showed that boys have higher blood pressure than girls significantly after the age of $16 .^{22}$ The evidence has shown that testosterone plays an important role in higher BP in male and estrogen in female plays an protective role. That is why female have higher blood pressure after menopause. ${ }^{23}$ Presence of a family history of HTN significantly increased the risk of HTN in offspring. The family history of hypertension in our study is significantly associated with the HTN in male students but the family history of hypertension is not significantly associated with female students. Previous study showed that those who have a family history of HTN were 2-3 times more likely to develop HTN than without family history. ${ }^{24}$

The high prevalence of overweight/obesity among the students might be due to less physical activity and higher consumption of more unhealthy, high fat foods, sweetened beverages and salty snacks and less milk, fruits and vegetables than recommended and exposure to persistent stress. Through our observation, we can say that students are more addicted to junk foods specially burgers, pizza and cold drinks which are common causes of obesity. Various studies have shown that dietary intake, physical activity and self-discipline are major factors influencing obesity and high blood pressure. ${ }^{25,26}$ These findings suggest that obese children are at higher risk of having high blood pressure than normal children. Therefore, obese children should be routinely screened for blood pressure and other coexisting cardiovascular risk factors including lipid profile. ${ }^{27}$ In addition, healthy lifestyles should be encouraged by college and at home since prevention in them can help to avoid undesirable health consequences in the future.

The expenses we are paying for comfortable and urbanized society causing inactive life style and unhealthy dietary habits which result in difference between energy consumption and expenditure which ultimately leads to obesity. ${ }^{28}$ Previous studies found high prevalence rates of cardiovascular risk factors, including components of metabolic syndrome, in undergraduate university students, with frequencies reaching $60 \% .^{29}$ The prevalence of both hypertension and obesity is a significant public health challenge and its trend is increasing throughout the world. This huge increase in prevalence of obesity is well documented as one of the major risk factors for the progress of hypertension. They are constant with the nationwide importance on prevention as well as control of weight and obesity. They also specify that measurement of blood pressure and body weight and timely diagnosis and control are exclusively essential for overweight and obese people.

\section{CONCLUSION}

The prevalence of systolic and diastolic blood pressure increases as BMI increases. The family history of HTN also increases the chance of getting HTN in offspring. So, the students who are obese and had family history of HTN should have timely intervention for reducing their weight and so decreasing their chances of hypertension. They should be closely monitored so as to pick the disease in early stages and get standard treatment accordingly.

\section{RECOMENDATIONS}

There is a strong correlation between BP and BMI. So, it is recommended to decrease $\mathrm{BMI}$ in order to decrease $\mathrm{BP}$.

\section{LIMITATIONS OF THE STUDY}

The current study only focused on students so the diverse age groups were not included. The daily physical activities were also not considered in the study which also has some influence in BMI and BP.

\section{ACKNOWLEDGEMENTS}

We would like to thank all the students who voluntarily agreed to participate in this study.

\section{CONFLICT OF INTEREST}

There is no any conflict of interest

\section{FINANCIALDISCLOSURE}

None

\section{REFERENCES}

1. Jain A, Jain A, Pankaj JP, Sharma BN, Paliwal A. The study of obesity among children aged 5-18 years in Jaipur, Rajasthan. $J$ Med Sci Res. 2016;7:125-30. DOI: 10.4103/0975-9727.185013

2. Kotian MS, Kumar SG, Kotian SS. Prevalence and determinants of overweight and obesity among adolescent school children of South Karnataka, India. Indian J Community Med. 2010;35:176-8. DOI: 10.4103/0970-0218.62587

3. Mungreiphy NK, Kapoor S and Sinha R. Association between BMI, Blood Pressure, and Age: Study among Tangkhul Naga Tribal Males of Northeast India. Hindawi Publishing Corporation. J of Anthropol. 2011;748147:1-6. DOI: 10.1155/2011/748147

4. S. O'Neill and L. O'Driscoll, "Metabolic syndrome: a closer look at the growing epidemic and its associated pathologies," Obesity Reviews. 2015;16(1):1-12. DOI: 10.1111/obr.12229 
5. Chinali M, de Simone G, Roman MJ, Best LG, Lee ET, Russell M et.al Cardiac markers of preclinical disease in adolescents with the metabolic syndrome: The strong heart study.J Am CollCardiol. 2008;52:932-8. DOI: 10.1016/j.jacc.2008.04.013

6. World Health Organization. World Health Report 2002: Reducing risks, Promoting Healthy Life. World Health Organization: Geneva, 2002.

7. New ACC/AHA High blood pressure guidelines lower definition of HTN. American college of Cardiology: Washington, DC; 2017 Nov.

8. Margaret A, Shiun DH. Six reasons why the waist-to-height ratio is a rapid and effective global indicator for health risks of obesity and how its use could simplify the international public health message on obesity. Int J Food SciNutr. 2005;56(5):303-307. DOI: 10.1080/IJFSN09637480500195066

9. Kumanyika SK, Landis JR, Matthews YL, Weaver SL, Harlan LC, and Harlan WR. Secular trends in blood pressure among adult blacks and whites aged 18-34 years in two body mass index strata, United States, 1960-1980. Am J Epidemiol. 1994;139(2):141-154. DOI: 10.1093/oxfordjournals.aje.a116976

10. Humayun A, Shah AS, Sultana R. Relation of hypertension with body mass index and age in male and female population of Peshwar, Pakistan. J Ayub Med Coll Abbottabad. 2009;21(3):63-5. PMID: 20929016

11. Schall JI. Sex differences in the response of blood pressure to modernization. Am J Hum Biol. 1995;7:159-172. DOI: 10.1002/ ajhb.1310070204

12. Bovet P, Ross AG, Gervasoni JP, Mkamba M, Mtasiwa DM, Lengeler $C$, et.al. Distribution of blood pressure, body mass index and smoking habits in the urban population of Dares Salaam, Tanzania, and associations with socioeconomic status. Int J Epidemiol. 2002;31(1):240-247. DOI: 10.1093/ije/31.1.240

13. Whitaker RC, Wright JA, Pepe MS, Seidel KD, Dietz WH: Predicting obesity in young adulthood from childhood and parental obesity. N Engl J Med. 1997;337(13):869-873. DOI: 10.1056/nejm 199709253371301

14. Hussein H. Alhawari, Sameeha Al-Shelleh, Hussam H. Alhawari Aseel Al-Saudi, Dina Aljbour Al-Majali, et,al. Blood Pressure and Its Association with Gender,Body Mass Index, Smoking, and Family History among University Students. Int J Hypertens. 2018;4186496: 1-5. DOI: $10.1155 / 2018 / 4186496$

15. Higgins M, Kannel W, Garrison R, Pinsky J, Stokes J 3rd. Hazards of obesity--the Framingham experience. Acta Med Scand Suppl. 1988;723:23-36. DOI: 10.1111/J.0954-6820.1987.tb05925.x

16. Rabkin SW, Chen Y, Leiter L, Liu L, Reeder BA. Risk factor correlates of body mass index. Canadian Heart Health Surveys Research Group. CMAJ. 1997;157:S26-31. PMID: 9220951

17. Huang Z, Willett WC, Manson JE, Rosner B, Stampfer MJ, Speizer FE, Colditz GA. Body weight, weight change, and risk for hypertension in women. Ann Intern Med. 1998;128:81-8. DOI: 10.7326/0003-
4819-128-2-199801150-00001

18. Stamler R, Stamler J, Riedlinger WF, Algera G, Roberts RH. Weight and blood pressure. Findings in hypertension screening of 1 million Americans. JAMA. 1978;240:1607-10. DOI: 10.1001/ jama. 240.15.1607

19. Juonala M, Magnussen CG, Berenson GS, Venn A, Burns TL, Matthew A Sabin, et.al. Childhood adiposity, adult adiposity, and cardiovascular risk factors. N Engl J Med. 2011;365:1876-85. DOI: 10.1056/NMJMoa1010112

20. Pan $H$, Jiang $Y$, Jing $X, F u S$, Jiang $Y$, Lin Z, et.al. Child body mass index in four cities of East China compared to Western references. Ann Hum Biol. 2009;36:98-109. DOI: 10.1080/03014460802575641

21. Chen LJ, Fox KR, Haase A, Wang JM. Obesity, fitness and health in Taiwanese children and adolescents. Eur J ClinNutr. 2006;60: 1367-75. DOI: 10.1038/sj.ejcn.1602466

22. Krzyzaniak A, Krzywinska-Wiewiorowska M, Stawinska-Witoszynska B, Kaczmarek M, Krzych L, Kowalska M, Szilagyi-Pagowska I, Palczewska I, Karch A, Josko J, Ostrowska-Nawarycz L, Nawarycz T. Blood pressure references for Polish children and adolescents. Eur J Pediatr. 2009;168(11):1335-1342. DOI: 10.1007/s00431-009-0931-2

23. Reckelhoff JF. Gender Differences in the Regulation of Blood Pressure. Hypertension. 2001;37:1199-1208. DOI: 10.1161/ 01.HYP.37.5.1199

24. Stamler R, Stamler J, Riedlinger WF, Algera G, Roberts RH. Family (parental) history and prevalence of hypertension. Results of a nationwide screening program. Jour. A M A. 1979;241(1):43-46. doi: 10.1001/jama.1979.03290270033016

25. Sirikulchayanonta C, Ratanopas W, Temcharoen P, Srisorrachatr S. Self-discipline and obesity in Bangkok school children. BMC Public Health. 2011;11:158. DOI: 10.1186/1417-2458-11-158

26. Dehghan M, Akhtar-Danesh N, Merchant AT. Childhood obesity, prevalence and prevention. Nutr J. 2005;4:24. DOI: 10.1186/14752891-4-24

27. Pearson TA, Palaniappan LP, Artinian NT, Carnethon MR, Criqui MH, Daniels SR, et.al. American Heart Association guide for improving cardiovascular health at the community level, 2013 update: A scientific statement for public health practitioners, healthcare providers, and health policy makers. Circulation. 2013;127:1730-53. DOI: 10.1161/cir.Ob013e31828f8a94

28. Saeed S, Ali A, Khawaj R, Shaikh IA, Shah I, Mustafa MW. Relationship between BMI and Blood pressure among student of 3rd year at institute of medical technology. Medical Channel. 2013;19(4):5-8.

29. Zea-Robles AC, Le'on-Ariza HH, Botero-Rosas DA, AfanadorCasta neda HD, and Pinz'on-Bravo LA, "University students' cardiovascular risk factors and their relationship with body composition, Revista de SaludP'ublica. 2014;16(4):505-515. DOI: 10.15446/rsap.v16n4. 